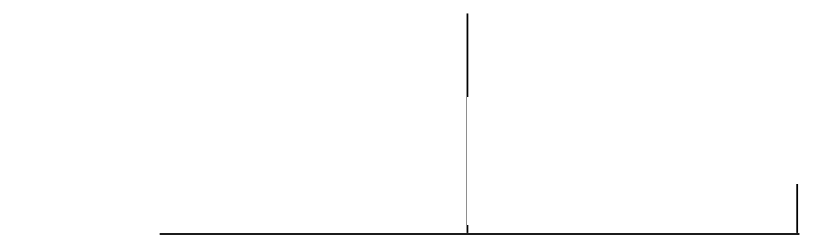

Rev. Latinoam. Psicopat. Fund., São Paulo, v. 13, n. 4, p. 667-679, dezembro 2010

\title{
A memória ventre da alma
}

\author{
Marina Massimi
}

O artigo aborda o tema da memória como proposto num sermão de Vieira (1654), buscando reconstruir as matrizes conceituais (a concepção de memória de Agostinho e de Bernardo) e práticas (a tradição da ortopraxis desenvolvida nas comunidades monásticas na Idade Média). Para ambos, a memória é concebida como processo ativo e abrangente, intimamente associada à emoção e à imaginação: não apenas rememora, mas organiza experiências e conceitos segundo um esquema norteado por lugares e percursos, tornando-os disponíveis para a invenção e a construção cognitiva.

Palavras-chave: Memória, Agostinho, Antônio Vieira, machina memorialis 


\section{Introdução}

Este artigo visa contribuir para a apreensão de alguns significados que a memória assumiu ao longo da história da cultura ocidental, seguindo a abordagem historiográfica proposta por De Certeau (1975). Esta associa o universo do pensável ao universo das práticas e articula a história das doutrinas com a sociologia dos comportamentos. Desse modo, investigar a história da memória implica o estudo das conceituações acerca dela, bem como as práticas que regraram seu funcionamento (veja-se, como exemplo, a longa história da arte da mnemotécnica, criada pelos gregos). $\mathrm{O}$ gênero da oratória sagrada, de que Vieira é a expressão mais alta na cultura brasileira, nutre-se pela intersecção desses dois universos: de modo que indagar o significado e o uso da memória neste contexto pressupõe necessariamente a compreensão de ambos.

\section{A memória em um sermão de Antônio Vieira}

No sermão do Rosário, pregado em 1654 (2000), na Igreja do Colégio Jesuíta de São Luís do Maranhão, “com o Santíssimo Sacramento exposto, no sábado da infra Octavam Corporis Christi e na hora em que todas as tarde se reza o Rosário", Antônio Vieira estabelece uma analogia entre o tema da festividade (a solenidade do corpo de Cristo) e o corpo humano. Retira a analogia do livro bíblico do Cântico dos Cantos e afirma que a Igreja católica, corpo místico de Cristo, pode ser considerada corpo vivo. Deste corpo vivo aborda a 'fisiologia', focando uma função decisiva para a sobrevivência: a função alimentar: 
E discorrendo particularmente por todos os membros e partes de que se compõe, com louvor da formosura, e declaração do ofício de cada um, chega finalmente àquela oficina universal, onde se recebe o alimento, e convertido em sangue se reparte por todo o corpo (2000, p. 31).

O ilustre pregador evidencia as possíveis significações espirituais do ato de alimentar-se e de seus efeitos fisiológicos (Massimi, 2006): neste âmbito, refere-se à memória atribuindo-lhe a função fundamental de "o estômago da alma". De fato, afirma que da mesma forma em que o estômago é o lugar do organismo onde "se recebe e se retém o comer corporal e ali se faz a primeira decocção dos alimentos" (p. 43), a memória é a primeira potência anímica que recebe e recolhe dentro de si, "por meio da apreensão", o conteúdo percebido pelos sentidos a ser elaborado pelo entendimento e pela vontade de modo a produzir conhecimento.

Por outro lado, este conteúdo melhor será elaborado, quando mais vagarosamente for apreendido: "lembrando-se não de passagem, senão muito devagar" (p. 43). Ou seja, a função nutritiva cujo processo depende da atividade do órgão do estômago-memória que preside o metabolismo digestivo, realiza-se da melhor forma se forem tomados alguns cuidados necessários ao bom funcionamento desse mesmo órgão. Com efeito, observa Vieira, "o mantimento corporal que se come, e não se digere, por mais substancial e esquisito que seja não faz nutrição, nem se converte em substância. Lá diz o aforismo vulgar da Medicina: Non quod ingeritur; sed quod digeritur" (p. 34).

Analogamente ao que acontece na fisiologia do corpo, também na "fisiologia anímica" (se assim a podemos chamar), o processo da nutrição "reparte por todas as veias e os membros do corpo a substância e a virtude do que se come" (p. 35). Disto decorre a assimilação do alimento "que se recebe não só no peito do corpo, senão no estômago da Alma e nele se digere"; "dali se difunde por todas as veias e reparte e comunica a todos os membros do nosso corpo a virtude e virtudes do corpo e membros de Cristo, que na substância e na realidade do que comemos se encerra" (p. 35).

O objetivo de Vieira é fundamentar nesta analogia, a tese acerca da eficácia da prática religiosa do Rosário, exercício devocional que "esmiúça" o conteúdo doutrinário em pequenas partes (cada um dos "mistérios" contemplados pelo devoto, ao longo do exercício). O funcionamento da memória e seu encadeamento com a atividade das demais potências psíquicas são descritos em pormenores para justificar adequadamente a tese proposta.

A memória, definida como o "estômago da alma", realiza a primeira "decocção" dos seus objetos, "lembrando-se não só de passagem, senão muito devagar (como se faz no corpo), e representando à Alma quem é o que está presente" no conteúdo a ser memorizado. De fato, a propriedade da memória é "fazer presentes as coisas ausentes" (p. 43). Esta é a potência que tem a

Rev. Latinoam. Psicopat. Fund., São Paulo, v. 13, n. 4, p. 667-679, dezembro 2010 


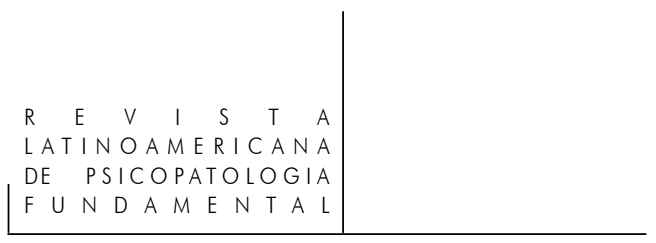

capacidade de "levar-nos aos ausentes, para que estejamos com eles, e trazê-los a nós, para que estejam conosco" (p. 43). Desse modo, a memória fazendo "presente" o que é "ausente", torna possível uma modalidade de presença que não é mais física e sim ocorre no nível do entendimento e da vontade: no nível do simbólico, diríamos hoje: "Lembrai-vos do amigo ausente que está em Portugal, e ao mesmo tempo vós estais lá com ele, e ele está cá convosco, porque lá nos levou a memória, e cá o tendes no pensamento" (2000,p. 44)

O dinamismo da memória articula-se ao das demais potências, exatamente como na "fábrica da nutrição" as operações principais são três: "uma que recebendo retém, outra que alterando assemelha, outra que unindo converte" (p. 42). Vieira afirma que estes conceitos derivam de Aristóteles e Galeno. Analogamente, "a potência da memória recebe e retém por meio da apreensão" o objeto, "a potência do entendimento alerta-o [o objeto, ndr.] e assemelha-o a si (ou a si a ele) por meio da meditação", "a potência da vontade converte e une em si mesma" este mesmo objeto. A atividade reflexiva do entendimento suscita o afeto amoroso na vontade. Vieira assemelha este afeto ao "calor natural" que no organismo permite a digestão (p. 47): dito calor "afetivo" é o que faz o sujeito "se incorporar pela vontade" ao objeto (p. 47).

Como o próprio Vieira declara, esta analogia não é sua invenção e sim retirada de toda uma ampla tradição cujos alicerces são: Platão (428-348 a.C.), a retórica romana, Agostinho (354-430), a tradição monástica medieval, o pregador e teólogo Bernardo de Claraval (1090-1153) e o pregador popular Bernardino da Siena (1380-1444).

\section{A memória segundo Agostinho}

Focalizamos agora a concepção de memória proposta por uma das fontes principais de Vieira: Agostinho, declarado por Vieira, no dito sermão, como sendo "o excelente filósofo da memória" (2000, p. 42).

Agostinho refere-se à memória como sendo "ventre da alma" em vários textos. É derivada destes textos a concepção exposta por Vieira de que a melhor maneira para que o "estomago da alma" funcione bem é a ruminação, ou seja, o modo de assimilação do alimento próprio dos bois, "que depois de comer tornam a ruminar, ou remoer aquilo mesmo que comeram", "muito devagar" (p. 48); o que facilita o processo digestivo.

Agostinho refere-se ao ato de "ruminar" e usa desta metáfora, repetidas vezes ao descrever o processo da memória (por exemplo: no discurso sobre o salmo 36; sobre o salmo 130). 
Nas "Confissões" (397) aplica o termo aos atos de memória que assumem um valor e um significado entre si muito diferentes. No "Livro Terceiro", ao referir-se ao início do relacionamento com a mulher que depois se tornou sua amante, Agostinho (397) afirma: "ela me seduziu porque me encontrou fora de mim, habitando nos olhos da minha carne e ruminando o que por eles tinha devorado" (p. 66). Neste contexto, a ruminação da memória refere-se à elaboração das imagens dos objetos sensíveis, alimentos estes que, porém, "não conseguiam saciar sua fome".

Já no "Livro Sexto", a ruminação da memória é aplicada ao "paladar espiritual" de Ambrosio e aqui a ruminação refere-se aos gozos interiores dos alimentos imperecíveis e espirituais: "Não tinha eu experiência da consolação nas adversidades e do paladar íntimo do coração com que ele saborosamente ruminava o pão dos vossos gozos" (p. 118).

Por fim, no "Livro Sétimo" Agostinho aplica o verbo ruminar ao ato da consideração filosófica dos argumentos dos adversários (no caso específico, tais argumentos justificariam os vaticínios dos astrólogos), num diálogo imaginário. Este ato por ele é considerado útil para construir sua própria posição e bem argumentar a refutação daquelas teses: "ruminava tudo isto comigo, para que nenhum desses loucos que viviam de tal negócio e que eu desejava atacar imediatamente e pôr a ridículo me pudessem resistir" (p. 148).

Em outra obra, o "Livro Sexto contra Fausto o Maniqueu" (410), ele refere-se ao ruminar pela memória como ao ato que, pela "doçura da lembrança" de um conteúdo ouvido e reconhecido como útil, evoca e transmite este conteúdo das "vísceras da memória para a boca do pensamento" (livro 06, par. 07, v. 11).

$\mathrm{Na}$ “Exposição acerca do Salmo 141" Agostinho (2010) detalha em pormenores seu entendimento do ato de ruminar a palavra. Parte da constatação de que, diante da palavra a ser aprendida, normalmente temos certa avidez que em muitos casos nos faz esquecer nossa própria fragilidade e limites intelectuais, bem como as limitações de quem nos comunica esta palavra. Diante disto, aconselha a "esconder a palavra ouvida no ventre da memória, tornando-a objeto de meditação vagarosa" (par. 01, v. 8). Ruminar significa voltar pelo pensamento ao que se ouviu, de modo a se apossar daquele conteúdo na profundidade do eu (no "homem interior"): assim o conceito aprendido coincidirá com a sua expressão vocal (o que ele chamara de "boca do pensamento"). Com efeito, para o orador Agostinho, pronunciar o verbo identifica-se com o pensar o conceito, sendo ambos expressivos da apreensão da única verdade.

Desse modo, para ele, o processo da memória deve ser balizado numa temporalidade própria e é voltado para a transmissão oral: a palavra fruto da elaboração do pensamento, que é a ruminação, é assim profundamente associada à atividade da memória. 


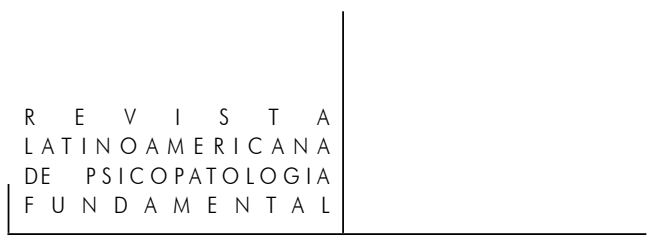

Agostinho (397) aborda amplamente o tema da memória no livro X das Confissões: aqui descreve a memória pela metáfora do "palácio": em seu espaço a memória retém as imagens trazidas pela percepção, como também todos os produtos do pensamento. A evocação dos conteúdos da memória é feita pela vontade: "Quando lá entro, mando comparecer diante de mim todas as imagens que quero" (p. 224). Apesar das diferentes imagens comparecerem com intensidades e tempos diferentes (algumas se apresentam imediatamente, outras mais vagarosamente, algumas se impõem à atenção, outras precisam ser extraídas; algumas "irrompem aos turbilhões", outras "em sério ordenada", é a escolha da vontade que as organiza, como Agostinho frisa repetidamente pelo uso de verbos como querer, apetecer etc.: "quando eu quiser", "se me apetece chamá-los", "conforme me agrada" etc.

Em primeiro lugar, Agostinho analisa a memória sensorial: esta é um palácio interiormente organizado, onde "se conservam distintas e classificadas todas as sensações que entram isoladamente pela sua porta" (p. 225), ou seja, pelos cinco sentidos. As imagens das coisas sensíveis que entram na memória nela permanecem "sempre prestes a oferecer-se ao pensamento que as recorda" (p. 225).

A memória é descrita também como "um grande receptáculo" formado por "sinuosidades secretas e inefáveis, onde tudo entra pelas portas respectivas e se aloja sem confusão" (p. 225). Na memória estão presentes todas as imagens do mundo real, derivada pelos sentidos.

Uma segunda função da memória é a de ser o lugar onde encontrar a si mesmo: a lembrança de ações, sentimentos, ideias, experiências vividas.

Em terceiro lugar, Agostinho trata da memória intelectual, que é a o repositório de todos os conhecimentos adquiridos. Neste caso também, ressalta a dimensão espacial da memória, caracterizando-a, porém, como espaço não físico e sim virtual: "estes conhecimentos serão como que retirados num lugar mais íntimo, que não é lugar" (p. 227), onde "as imagens [dos objetos, ndr.]. são recolhidas com espantosa rapidez e dispostas, por assim dizer, em células admiráveis, donde admiravelmente são tiradas pela lembrança” (p. 227). Aqui está o princípio daquela que será a arte da mnemotécnica, amplamente utilizada no Ocidente medieval, renascentista e aos inícios da Idade Moderna.

Nas "concavidades secretíssimas" (p. 228) e mais retiradas da memória estão as noções inatas, ou seja , as que não são derivadas pelas imagens sensoriais e sim que "vemos em nosso interior tais quais são em si mesmas". A aprendizagem destas noções que a memória retém de modo desordenado e disperso consiste em "coligi-las pelo pensamento" e "obrigá-las pela força da atenção, a estarem sempre como que à mão, e a se apresentarem com facilidade ao esforço costumado do nosso espírito" (p. 229). Neste caso, o exercício é fundamental, pois "se deixar de as recordar, ainda que seja por pequeno espaço de tempo, de novo imergem 
e como que escapam para esconderijos mais profundos" (p. 229). Aqui Agostinho estabelece uma interessante relação entre a atividade de coligir estas noções dispersas e a etimologia do verbo latim cogitare que significa pensar. Da mesma forma, a memória retém números e figuras geométricas.

A memória lembra de sua própria atividade e encerra em si os afetos da alma, mas "não da maneira como os sente a própria alma, quando os experimenta, mas de outra muito diferente, segundo o exige a força da memória" (p. 230).

Neste ponto, Agostinho retoma a metáfora da memória como sendo o "ventre da alma", ao explicar a razão do fato que os afetos vivenciados são modificados pela memória: "A memória é como o ventre da alma. A alegria, porém, e a tristeza são o seu alimento, doce ou amargo. Quando tais emoções se confiam à memória, podem ali encerrar-se depois de ter passado, por assim dizer, para esse estômago; mas não podem ter sabor" (p. 231). De modo que eu posso apoiar-me na memória para reconhecer as "quatro perturbações da alma" (p. 231), a saber, desejo, alegria, medo e tristeza, mas ao fazê-lo "não me altero com nenhuma daquelas perturbações quando as relembro com a memória” (p. 231). E continua: "Assim como a comida graças à ruminação, sai do estômago, assim também elas saem da memória, devido à lembrança”, mas ao serem recordadas elas não trazem "à boca do pensamento, a doçura da alegria nem a amargura da tristeza" (p. 231). De fato, isto é necessário para que tenhamos a vontade de lembrar, pois "quem de nós falaria voluntariamente da tristeza e do temor, se fôssemos obrigados a entristecer-nos e a temer, sempre que falamos da tristeza ou temor?" (p. 232). Todavia, estes sentimentos também são retidos na memória: da memória tiramos o som das palavras utilizadas na conversa, conforme as imagens gravadas pelos sentimentos corporais, mas também a noção dos sentimentos àquelas associados, que estão igualmente retidos nela.

A "força" ou "potência da memória" é retratada por Agostinho como sendo idêntica à dimensão mais essencial do homem, "o eu mesmo", "uma vida variada de inúmeras formas com amplidão imensa" (p. 234). Devido à vastidão e complexidade da memória, Agostinho utiliza-se também de outra metáfora espacial: "eis-me nos campos de minha memória" que "percorro" indo "por aqui e por ali" (p. 234), penetrando "por toda a parte quanto posso, sem achar fim". Adentra assim "nos seus antros e cavernas sem número" e descobre que eles são ocupados por "presenças": "repletas, ao infinito, de toda a espécie de coisas que lá estão gravadas, ou por imagens como os corpos, ou por si mesmas como as ciências e as artes, ou então por não sei que noções e sinais, como os movimentos da alma, os quais, ainda quando não a agitam, se enraízam na memória, posto que esteja na memória tudo o que está na alma" (p. 234). Ao percorrer os campos da memória, porém, o ser humano não se satisfaz com os achados proporcionados pelo aspecto da memória que é comum também aos animais: esta funciona como 


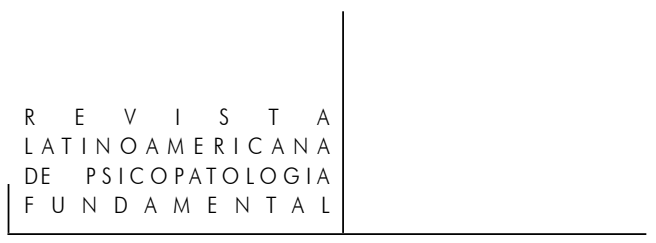

sistema de referência para a vida cotidiana, permitindo-nos adquirir hábitos e regressar a lugares corriqueiros. Além disto, o homem procura na memória o que mais profunda e ardentemente deseja, a saber, a "felicidade real", "a felicidade em concreto" (p. 237), esta felicidade que "os homens de todas as línguas têm um desejo ardente de alcançar" (p. 238). Cada ser humano ao ser perguntado se quer ser feliz, pode sem hesitação responder que sim, pelo fato de que em sua memória conserva a lembrança real do que a palavra felicidade significa. A memória é, portanto, o lugar onde o homem busca encontrar não somente o saber, como também a vida.

\section{As práticas da memória}

Essa dimensão existencial da memória reencontra-se, muitos séculos depois, nos escritos de Bernardo de Claraval (1090-1153). No Sermão trigésimo sexto sobre o conhecimento e a ignorância, Bernardo retoma a metáfora da memória estômago da alma e enfatiza a função do afeto neste processo: o "fogo do amor" é essencial para cozer os alimentos no aparelho digestivo da alma. De outro modo, ter-se-á um "saber indigesto" pela presença de "humores maus e nocivos" (Lauand, 1998, p. 267) causadores de "inchaços e cólicas de consciência" (p. 268). O que seria esse alimento indigesto? Trata-se de um saber desvinculado do bem viver: articulação ideal entre vida e saber própria de toda a tradição medieval. O bom uso da memória moldada pelo desejo do bom e pela vontade de alcançar a felicidade é tido, portanto, como elemento essencial para realizar o alimento saudável que corresponde ao verdadeiro conhecimento, à verdadeira filosofia.

Entre Agostinho e Bernardo, há um trabalho secular que manteve viva esta concepção e esta prática da memória, trabalho que Carruthers (2006) identifica como realizado extensivamente pelas comunidades monásticas ao longo do período medieval. Esta autora, em contraste com a tese clássica de Yates (1966) que enfatizara o caráter repetitivo e mecânico da arte da memória, aponta para a importância dos exercícios da meditação monástica, como suporte na elaboração dos processos cognitivos em culturas orais. Carruthers evidencia o nexo da memória com a inventio e a mediação que a memória exerce na composição mental de um percurso que pode ser puramente mental ou real. As técnicas da memória nesta perspectiva assumem uma função relevante na modalidade de leitura e assimilação de textos que são transformados em patrimônio interior e nela armazenados de modo a serem reutilizados na criação de novos textos como também na tomada de decisões morais. As técnicas da arte da memória próprias 
da tradição da retórica clássica interagem assim com as práticas monásticas da meditação ensinando a criar "lugares" mentais, onde colocar lembranças de coisas lidas ou ouvidas e dos quais tirar materiais e associações para novos pensamentos, novas palavras e novos atos. Trata-se do processo que Agostinho definira como a "força da memória": a construção mental de lugares, palácios, jardins, itinerários a serem percorridos. A memória atua assim como um grande arquivo capaz de se reproduzir e gerar; é capaz de mobilizar afetos e proporciona conservação e invenção.

A arte da memória assim concebida não funciona apenas como meio persuasivo e sim como recurso para a invenção e para a construção do pensamento. Retoma-se, nesta perspectiva, o significado etimológico da palavra latina inventio - uma das componentes fundamentais da arte retórica - que assume o duplo significado de inventar e de inventariar, recolher e ordenar a informação.

Este exercício realiza aquilo que Carruthes define uma ortopraxis, ou seja, um itinerário que possibilita um reacontecer da experiência do fundador semelhante à originária. Trata-se da aprendizagem de uma prática que cria familiaridade com a experiência que a promove. Dito percurso educativo, ou seja, a experiência disciplinada, permite ao aprendiz identificar-se com uma vivência reconhecida como original e fundante. A memória desta origem envolve um dinamismo amplo em que participam rememoração, emoção, imaginação e meditação. Trata-se de uma construção do pensamento proporcionada pela vivência comunitária que norteia certo uso da retórica como inventio, como arte da composição, da meditação resultante de uma atividade cognitiva disciplinada: o silentium. Com efeito, já Agostinho considerava a meditação a forma mais alta de eloquência.

Nesta perspectiva, a memória não é concebida tanto como repetição ou reprodução de algo quanto como matriz de uma atividade cognitiva em que as lembranças são mescladas e associadas num esquema mnemônico, numa arquitetura da memória, ou machina memorialis. Trata-se de uma concepção da memória que muito se aproxima daquela própria da tradição retórica romana: não se trata tanto da arte da repetição quanto da arte da invenção, que possibilita ao usuário o saber usar a palavra apropriadamente em qualquer circunstância. Não se trata, portanto, de uma memória estática e repetitiva, mesmo quando assume a feição da memória artificial, ou mnemotécnica (Yates, 2002). Memória e arte da composição são profundamente associadas: a invenção, o pensamento criativo são relacionados assim profundamente à arte da retórica. O termo invenção (inventio) tem um duplo significado de criar algo novo e de inventariar, colocar as ideias na ordem em determinados lugares que permitem sejam reencontradas facilmente: trata-se de uma memória que localiza. A memória funciona muito menos como estrutura temporal que como lugar para dispor as coisas, através de 


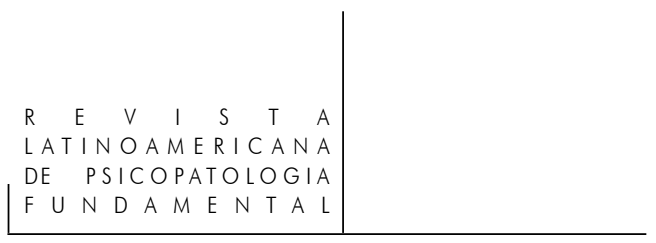

seus sinais ou indícios que tomam forma de imagens mentais, tendo intenso componente afetivo.

Esta concepção não mecanicista da memória e de suas possibilidades alcançadas pelo exercício proporciona uma mais ampla compreensão do uso das imagens mentais e das articulações entre as relações entre memória e imaginação. Com efeito, por um lado, a visualização do pensamento em esquemas organizados de imagens aproxima estes métodos a tópicos importantes da psicologia contemporânea e, por outro, esta concepção de memória ativa (e não apenas repetitiva) que constrói esquemas de imagens para organizar seus conteúdos remete à memória coletiva, sendo estes esquemas e lugares expressão de fenômenos sociais e culturais influentes na construção desta arquitetura mental. No que diz respeito especificamente às imagens e à imaginação, segundo a perspectiva metodológica proposta por Carruthes, a criação das imagens mentais não é sugerida tanto pela imitação e semelhança aos objetos que devem representar, quanto pela função cognitiva a ser desenvolvida: por exemplo, o fato de que um ponto é mais facilmente localizável se pertencer a um conjunto (exemplo: uma estrela numa figura de constelação como urso, carro etc.); ou se pertencer a certa narrativa, a certa história (conforme hoje a psicologia moderna confirma pelos experimentos de F.C. Bartlett). A eficácia mnemônica destas narrativas é aumentada quanto mais forem afetivamente intensas e cognitivamente inusitadas.

No dinamismo da memória, portanto, a imagem ocupa um lugar específico não tanto pelo seu conteúdo quanto pela sua forma. A prática monástica da meditação resulta na fabricação de imagens mentais ou de quadros cognitivos utilizados para pensar e compor. De fato, o monaquismo frisa a necessidade de que as pessoas visualizem os pensamentos em suas mentes através de esquemas organizados de imagens. As imagens da memória são compostas por dois elementos: uma semelhança que sinaliza a experiência a ser lembrada e uma intentio, ou seja, a inclinação para com esta experiência, importante para classificá-la e reencontrá-la: por isto, as lembranças são constituídas por imagens com intenso componente emocional. Em suma, nesta tradição retórica, a construção das imagens mnemônicas obedece não a regras de conteúdo e sim de forma: devem servir para compor relações e redes de relações úteis para reter conceitos importantes e para auxiliar descobertas. É uma específica configuração e a posição nela ocupada pela imagem mental que permite a memorização; as redes e os lugares desta configuração pertencem a inventários sociais e mentais que proporcionam mapas de orientação dos pensamentos e das condutas.

A imagem é, assim, uma espécie de veículo dos conteúdos da memória, sendo a imaginação usada para construir estes mapas e para decifrar os percursos sugeridos. Exemplificando, na Idade Média, as peregrinações para determinados lugares e as procissões de fiéis seguindo determinadas imagens nos andores não 
eram relevantes pela autenticidade histórica dos lugares e das imagens, mas pelo fato de essas práticas proporcionarem o reconhecimento de imagens da memória, de modo que "a atividade física do deslocamento de um lugar para outro, espelhava fielmente a atividade mental na qual se empenhavam os participantes da procissão" (Carruthers, 2006, p. 68; tradução livre). As imagens, reconhecidas não tanto pelo seu conteúdo e sim pela sua função, são utilizadas como suportes para o pensamento: inclusive sua forma estética e os apelos sensoriais e afetivos por ela suscitados, são funcionais ao pensamento.

\section{Conclusão}

A abordagem proposta por Carruthers ilumina também a consideração de práticas culturais e religiosas difundidas no Brasil colonial: nestas podemos reconhecer um dinamismo análogo. Trata-se aqui também do emprego de uma máquina retórica visando transmitir e ensinar certo tipo de elaboração da experiência a ser memorizada e reinventada. Esta máquina é utilizada pelas congregações, irmandades e ordens religiosas atuantes na sociedade colonial que se apoiam na memória coletiva de vivências e tradições culturais e elaboram e reinventam práticas dessas tradições, acomodadas ao contexto em que deverão ser efetivadas. Portanto, a mobilização do dinamismo psíquico dos destinatários para a elaboração da experiência ocorre em conformidades a tais matrizes. Assim, quando Vieira em seu belo sermão introduz a devoção do Rosário como sendo ruminação dos mistérios que compõem a Sagrada Ceia e que vagarosamente devem ser ingeridos para poderem ser digeridos pela memória, ventre da alma, ele inspira-se em Agostinho e Bernardo e também fundamenta-se na tradição da machina memorialis transmitida através das gerações e apropriada por Inácio e pela Companhia de Jesus, conforme documenta a fonte mais significativa que da experiência jesuítica propõe-se a ser, formadora e modelo: os "Exercícios Espirituais".

\section{Referências}

Agostinho, A. (397). Confissões. Trad. J. Oliveira Santos e A. A. de Pina. Petrópolis, RJ: Vozes, 1988.

Agostinho, A. (410). Contro Fausto Manicheo. Disponível em: <http:// www.augustinus.it/italiano/contro_fausto/index2.htm>. Acesso em: 29 out. 2010. 
. Esposizione sul Salmo 141. Disponível em: <http://www.augustinus.it/ italiano/esposizioni_salmi/index2.htm>. Acesso em: 20 out. 2010.

CARruthers, M. Machina memorialis. Meditazione, retorica e costruzione delle immagini. Pisa: Edizioni della Scuola Normale, 2006

De Certeau, M. (1975). A escrita da história. Trad. M.L. Menezes. Rio de Janeiro: Forense Universitária, 2002.

Lauand, L.J. Cultura e educação na Idade Média. São Paulo: Martins Fontes, 1998.

Massimi, M. Alimentos, palavras e saúde (da alma e do corpo), em sermões de pregadores brasileiros do século XVII. História, Ciências, Saúde-Manguinhos, Rio de Janeiro, v. 13, n. 2, p. 253-270, 2006.

VieIRA, A. Sermões. (Organizador: A. Pécora). São Paulo: Hedra, 2000. Tomo segundo, p. 31-52.

YAtEs, Fr. (1966). L'arte della memória. Trad. A. Biondi. Torino: Einaudi, 2002.

\section{Resumos}

(Memory, womb of the soul)

This article approaches the theme of memory as proposed in a sermon by Father Vieira (1654), where he reconstructs conceptual matrixes (St. Augustine's and St. Bernard's conceptions of memory) and practices (the orthopraxis tradition developed in monastic communities of the Middle Ages). For both thinkers, memory is conceived as an active and comprehensive process and is intimately associated with emotion and imagination. It not only recalls; it also organizes experiences and concepts according to a scheme oriented by places and routes, making them available for invention and cognitive construction.

Key words: Memory, Augustine, Antonio Vieira, machina memorialis

(La mémoire, ventre de l'âme)

Cet article étudie le sujet de la mémoire tel comme articulé dans un sermon de Vieira (1654), en cherchant de retracer les bases conceptuelles (la conception de mémoire chez Augustin et chez Bernard) bien que la tradition des pratiques (la tradition d'orthopraxie développée dans les communautés monastiques du Moyen $\hat{A}$ ge). Selon ces deux auteurs, la mémoire est conçue comme processus actif et global, intimement associée à l'émotion et à l'imagination: elle ne rappelle pas seulement, mais organise aussi l'expérience et les concepts selon un schéma balisé par des lieux et des parcours en les rendant disponibles à l'invention et à la construction cognitive.

Mots clés: Mémoire, Augustin, Antônio Vieira, machina memorialis

$$
\text { Rev. Latinoam. Psicopat. Fund., São Paulo, v. 13, n. 4, p. 667-679, dezembro } 2010
$$


(La memoria, vientre del alma)

Este artículo aborda el tema de la memoria, tal como fue propuesto en un sermón de Vieira (1654), buscando reconstruir sus matrices conceptuales (el concepto de memoria en Agustín y en Bernardo) y prácticas (la tradición de la ortopraxis, desarrollada por las comunidades monásticas de la Edad Media). Para ambos autores la memoria es concebida como un proceso activo e abarcador, intimamente asociado a la emoción y la imaginación: no sólo rememora, sino que, además, organiza experiencias y conceptos, según un esquema orientado por lugares y trayectos, lo que los torna disponibles para la invención y la construcción cognitiva.

Palabras clave: Memoria, Agustín, Antônio Vieira, machina memorialis

Citação/Citation: Massimi, M. A Memória ventre da alma. Revista Latinoamericana de Psicopatologia Fundamental, São Paulo, v. 13, n. 4, p. 667-679, dez. 2010.

Editor do artigo/Editor: Prof. Dr. Paulo José Carvalho da Silva

Recebido/Received: 30.10.2010 / 10.30.2010 Aceito/Accepted: 3.11.2010 / 11.3.2010

Copyright: (C) 2009 Associação Universitária de Pesquisa em Psicopatologia Fundamental/ University Association for Research in Fundamental Psychopathology. Este é um artigo de livre acesso, que permite uso irrestrito, distribuição e reprodução em qualquer meio, desde que o autor e a fonte sejam citados/This is an open-access article, which permits unrestricted use, distribution, and reproduction in any medium, provided the original author and source are credited.

Financiamento/Funding: $\mathrm{O}$ autor declara não ter sido financiado ou apoiado/The author has no support or funding to report.

Conflito de interesses/Conflict of interest: O autor declara que não há conflito de interesses/The author declares that has no conflict of interest.

\section{Marina Massimi}

Professora titular da Faculdade de Filosofia, Ciências e Letras de Ribeirão Preto da Universidade de São Paulo - FFCLRP-USP.

Rua Américo Brasiliense, 1340/111

14015-050 Ribeirão Preto, SP

e-mail: Mmassimi3@yahoo.com.

Rev. Latinoam. Psicopat. Fund., São Paulo, v. 13, n. 4, p. 667-679, dezembro 2010 